\section{HIGH INTENSITY ACOUSTIC TESTING OF FLIGHT STRUCTURES}

\author{
RALPH M. SHIMOVETZ \\ KENNETH R. WENTZ \\ Structural Dynamics Branch \\ Wright Laboratory \\ United States Air Force
}

\section{ABSTRACT}

High intensity acoustic testing has been an important part of Air Force technology for nearly thirty years. With the advent of jet aircraft in the 1950s, acoustic fatigue of aircraft structures became a significant problem. In the 1960 s the Wright Laboratory constructed the first large acoustic fatigue test facilities in the United States, and the laboratory has been a dominant factor in high-intensity acoustic testing since that time. In addition to fatigue of jet aircraft structures, other severe acoustic environments have been identified. Of particular importance are the acoustic environments of missiles in captive carry on fighter aircraft, and the high-temperature acoustic environments of blown flaps, hypersonic structures, and engine exhaust structures of stealthy aircraft. This paper describes the causes of these intense dynamic environments and some of the new facilities designed for tesing structures subjected to these dynamic loads. The Wright Laboratory facilities now include three new chambers: 1) a sub-element acoustic chamber for testing structural panels up to $12^{\prime \prime} \times 18^{\prime \prime}[.30 \times .46 \mathrm{~m}], 2$ ) a combined environment acoustic chamber for panels up to $4^{\prime} \times 4^{\prime}[1.23 \times 1.23 \mathrm{~m}]$, both at acoustic levels of $175-180$ $\mathrm{dB}$ and heat fluxes of 50 to several hundred Btu per square foot per second $\left[5000 \mathrm{~W} / \mathrm{m}^{2}\right]$, and 3) a random fatigue chamber for vibration testing of structural coupons up to $3^{\prime \prime} \times 7^{\prime \prime}[.08-.2 \mathrm{~m}]$ at temperatures from $-250^{\circ} \mathrm{F}$ to $+2700^{\circ} \mathrm{F}\left[120^{\circ} \mathrm{C}-1470^{\circ} \mathrm{C}\right]$ at atmospheric or lower pressures in the present of hydrogen and helium gases.

\section{Acoustic Fatigue in Aircraft Structures}

The Wright Laboratory has long been a leader in the technologies required for aircraft structures, and one of these driving technology areas is that of the dynamic environments of acoustics and vibration. Until the $1950 \mathrm{~s}$, the main emphasis in structural dynamics had been the control of sinusoidal vibration from reciprocating engines and from helicopter rotors. The electrodynamic shakers, vibration measurement equipment, and dynamic response analyses of those days were designed to handle combinations of sinusoidal forces related to blade passage frequencies and piston engine rotation frequencies.

With the advent of long-range jet aircraft flying at nearly the speed of sound, random vibration and acoustic inputs became much more important. The first indications of the severe acoustic environments experienced by jet aircraft were the problems of the $\mathrm{KC}-135$ fuselage fatigue and the B-52 wing structure, which showed cracking failures much sooner than expected. After extensive study and flight measurements, the acoustic environments were shown to be a severe combination of inputs from several sources, including jet noises, boundary layer noise, and disturbed air flow around control surfaces and other protuberances. The general trends of aircraft combined environments are shown in Figure 1. These acoustic inputs typically reach levels of 160-180 dB, which are much higher than previous aircraft environments. These are very severe acoustic levels, because even $140 \mathrm{~dB}$ sound pressure levels can cause acoustic fatigue and cracking of aircraft secondary structures.

To deal with these new acoustic environments, Wright Laboratory researchers reviewed the state of the art in acoustic testing, and the laboratory constructed its Sonic Fatigue Facility in the 1960s. Kolb and Rogers developed plans for the facility, and the final form is described in Kolb and Magrath (1968). This facility is now operated by the Structural Dynamics Branch. A schematic of the branch facilities is shown in Figure 2. The centerpiece of the test facility was the large scale test chamber, a reverberant chamber with a volume of 155,000 cubic feet, [4390 cubic meters]. The acoustic input was originally provided by 36 air sirens, each producing sound from air flowing through slots opened and closed by rotating and static disks. Each siren covered a narrow frequency band, and the combination provided the broadband acoustic output. The sirens have been replaced by electropneumatic modulators with broadband random acoustic outputs.

The original sonic fatigue facility included a quarter-scale reverberant chamber whose dimensions are one-fourth of the large chamber, and a small chamber for testing much smalier specimens. The quarter-scale and small chambers are configured as progressive wave tubes, in which the air flow from a compressor has acoustic energy added to it by the air modulator, is expanded through an exponential horn, propagates through a tube of rectangular-crosssection, and impinges on the test structure, which comprises one wall of the tube. The acoustic energy is absorbed in a termination section composed of acoustic absorption wedges, and the air is exhausted to the atmosphere. Progressive wave tubes are able to generate more accurate simulations of acoustic inputs impinging on flight structures than reverberant chambers, and are now the most common type of high-intensity acoustic test chambers.

Intense Acoustic Environments of Missiles in Captive Carry

In recent years, $\mathrm{Air}$ Force front-line fighter aircraft such as the F-15 have been called upon to carry newer, more capable missiles like the Advanced Medium-Range Air-to-Air Missile, or AMRAAM. Because of the speed and maneuverability of the $\mathrm{F}-15$, the missiles are subjected to very severe acoustic environments even before they are launched, when they are in captive carry under the F-15 wings. Wright Laboratory engineers measured the captive-carry AMRAAM environment on F-15s and found it to reach overall sound-pressure levels of $175 \mathrm{~dB}$ over frequencies of 30 to $2000 \mathrm{~Hz}$.

To test the missile to realistic levels, the simplest solution was to remove the fins and insert the missile into a 12 -inch-diameter $[.30 \mathrm{~m}]$ progressive wave tube driven 
by 3 Wyle WAS-3000 air modulators. The missile was mounted on its launcher for a realistic mounting condition. Figure 3 shows the schematic of the missile in the tube, and also shows the required test spectrum as a solid line and the achieved third-octave sound pressure levels with x's.

This test represented the highest broadband acoustic levels ever achieved for a missile. As a result of testing by the Wright Laboratory and government and contractor flight testing of AMRAAM structures, the missile was successfully modified by the contractor and qualified for flight under the entire flight envelope of the F-15. The AMRAAM will also be the main armament of the new Air Force advanced tactical fighter, the F-22.

High-Temperature Acoustic Environments from STOL and Stealth

To achieve short takeoff distances and rapid climb rates, new aircraft have been designed with larger flaps for additional lift. The lift from the aircraft wing and flap is limited by the velocity and volume of air flowing beneath the surface, and this lift can be augmented by flowing additional air from the engine across the lifting surface. This was first applied in the YC-14 and the YC-15 shorttakeoff and landing (STOL) aircraft prototypes in the early 1970s, and is now being used in the Air Force C-17 airlifter.

However, augmenting the lift by using engine exhaust gas subjects the wing and flap structure to intense noise and temperature inputs. An example from the $\mathrm{YC}-14$ is shown in Figure 4. In addition to raising the acoustic input from the typical level of $155 \mathrm{~dB}$ to about $165 \mathrm{~dB}$, the augmented lift subjects the structures to temperatures of $500-700^{\circ} \mathrm{F}\left[260-370^{\circ} \mathrm{C}\right]$. Many structures can withstand high dynamic forces at normal temperatures, but lose their strength rapidly at higher temperatures. New, high-temperature structures must be designed and tested to this combination environment, or the fatigue lives of these high-lift devices will be limited, increasing the maintenance costs of the aircraft.

To achieve stealthier aircraft, modern designs such as the F-117 fighter and the B-2 bomber use a variety of techniques to reduce their radar and infrared signatures. To reduce the emission of infrared energy from the heat of the engine exhaust toward the ground, these aircraft are designed with multiple engine nozzles that exhaust over the top of the aft structure so that the exhaust gases are cooled before they become visible from beneath the aircraft.

The result of this is that the aircraft aft structures are subjected to high-temperature acoustic environments much like the blown flaps of STOL aircraft. Stealthy aircraft, like STOL aircraft, need materials and structures that can maintain their strength and fatigue resistance at higher temperatures. This translates into requirements for flight testing of the actual environments and for developing laboratory test facilities for high-temperature fatigue testing.
Thermo-Acoustic Environments of Hypersonic Vehicle Structures

Hypersonic vehicles will operate at much higher dynamic pressures than conventional vehicles, leading to severe acoustic environments associated with both turbulent boundary layer and high thrust engines. Intense thermal fluxes will be present over large areas of the airframe, increasing the potential for acoustic fatigue damage. Local flow separation and shock impingement will aggravate both the acoustic and the thermal environments.

The initial predictions of the thermo-acoustic environments and heating levels, or $Q$, for typical hypersonic vehicles range from a $Q$ of $20 \mathrm{Btu}$ per square foot per second $\left[2000 \mathrm{~W} / \mathrm{m}^{2}\right]$ on the upper body to a $\mathrm{Q}$ of more than $500\left[50,000 \mathrm{~W} / \mathrm{m}^{2}\right]$ on the aifframe nozzle. The corresponding acoustic levels range from $150 \mathrm{~dB}$ up to an unprecedented $190 \mathrm{~dB}$ for the nozzle. There are no existing facilities that can duplicate these dynamic environments, and these acoustic test requirements are the most challenging yet encountered by the Wright Laboratory.

\section{The Air Force Wright Laboratory Acoustic Test Facilities}

The Structural Dynamics Branch of the Wright Laboratory is responsible for acoustics and vibration testing of aircraft. To meet the test requirements of these new classes of vehicles--STOL, stealth, and hypersonicthe branch is greatly increasing its capability for highintensity acoustic testing of flight structures by building three new test chambers. Two of the new chambers incorporate high-flux heating and multiple acoustic drivers into new progressive wave tubes; the third combines shaker fatigue testing with a temperature- and pressurecontrolled environmental chamber

The Random Fatigue Chamber provides the capability to determine the random fatigue characteristics and damage mechanisms of advanced material coupons and structural sub-elements. A schematic of the chamber is shown in Figure 5. The facility consists of an electrodynamic shaker that can produce a random force output of 20,000 pounds $[89,000$ N] RMS, coupled with an environmental chamber capable of operating from $-250^{\circ} \mathrm{F}$ to $2600^{\circ} \mathrm{F}\left[-157\right.$ to $1430^{\circ} \mathrm{Cl}$ with variable atmospheric pressure and partial pressure gas environments. This chamber is now on-line and is being used to generate stress vs. cycles to failure data and determine the influence of temperature, pressure and gases on materials and coating systems for hypersonic structures.

The Sub-Element Acoustic Chamber provides a progressive wave tube for response and fatigue testing of structures up to 12 " $[.30 \times .46 \mathrm{~m}]$ by 18 "at temperatures up to $2500^{\circ} \mathrm{F}\left[1370^{\circ} \mathrm{C}\right]$ and sound pressure levels up to $180 \mathrm{~dB}$ overall. A schematic of the chamber is shown in Figure 6.

The high-intensity acoustic environment is generated by four Wyle WAS- 3000 air modulators connected by exponential homs to a one-foot-square 
progressive wave tube. The low-flux thermal environment is provided by banks of quartz lamps incorporated inside the acoustic chamber. New mounting systems have been designed to allow modified lamps to survive the acoustic environment in order to be as close to the test specimens as possible. This technique eliminates the large, expensive quartz window used in previous hightemperature acoustic test facilities. The quartz lamps can provide input fluxes of up to a $Q$ of about 100 Btu per square foot per second $\left[10,000 \mathrm{~W} / \mathrm{m}^{2}\right]$.

Higher heat fluxes can be achieved by using graphite heaters or plasma arc lamps, both of which have been investigated. In addition, propane burners were also investigated, but were abandoned. Graphite heaters have the potential for reaching a $Q$ of $200\left[20,000 \mathrm{~W} / \mathrm{m}^{2}\right]$, and the plasma arc shows promise of reaching up to a $\mathrm{Q}$ of $1000\left[100,000 \mathrm{~W} / \mathrm{m}^{2}\right]$

The Combined Environment Acoustic Chamber is the third new capability being developed. The chamber, shown in Figure 7, was first operated in July, 1993. It provides a high-temperature acoustic progressive wave tube for response and fatigue testing of larger structural components. The chamber is driven by twelve WAS-3000 air modulators supplied by two air compressors.

The chamber is designated for two test sections. The four-foot section is designed for testing actively cooled structures at temperatures up to $3000^{\circ} \mathrm{F}\left[1650^{\circ} \mathrm{C}\right]$ and sound pressure levels up to $180 \mathrm{~dB}$. The six-foot test section will be added later, and is designed to provide the capability for elevated temperature testing of larger structures at $175 \mathrm{~dB}$. Low heat fluxes will be achieved using quartz lamps, and higher fluxes will be achieved with plasma arc heaters.

The development of these new high-temperature acoustic and vibration test chambers will maintain the Wright Laboratory at the forefront of structural dynamics testing of aircraft structures, making the laboratory capable of testing structures for all the critical flight vehicle applications now envisioned. This continues a long history of leadership for the Wright Laboratory in acoustic testing. The Combined Environment Acoustic Chamber is designed to achieve a noise level of $180 \mathrm{~dB}$, or nearly 3 psi $\left[2064 \mathrm{~N} / \mathrm{m}^{2}\right]$, on the test specimen. If this energy were concentrated into one frequency of, say, 100 $\mathrm{Hz}$, it would correspond to a fluctuating load of 1700 pounds of force $[7700 \mathrm{~N}]$ over a two-foot-square test panel, reversing from $+1700 \mathrm{lbs}$ to $-1700 \mathrm{lbs}[+7700 \mathrm{~N}]$ one hundred times per second. Such levels show the intense acoustic environments that must be withstood by modern flight structures.

\section{PROBLEMS}

Acoustic tests present additional problems over the vibration shaker tests because of the widespread high vibration levels on all components in the facility and high noise levels outside the test duct areas. SPL from $120 \mathrm{~dB}$ are exhibited for large areas around the test section. Recent experience has shown little signal degradation at $130 \mathrm{~dB}$; but serious damage of the laser vibrometers at $150 \mathrm{~dB}$ exposure levels. This can limit the usefulness for large scale acoustic fatigue testing. Simple static pressure transducer also show high sensitivity to vibration. One $1000 \mathrm{psi}$ transducer has a specification of $30 \mathrm{~g}$ 's for 11 milli-second. Several acceleration measurements showed vibration levels of $25 \mathrm{~g}$ 's on the test fixture and all transducers failed in a few hours of operation.

The laser vibrometer technique offers advances in non-contact measurement techniques. There are still some problems to overcome. For the laser vibrometer to operate correctly, the laser beam must be within a few degrees of perpendicular to the test specimen. The vibrometer must also be able to see the test specimen. This can be a significant problem when doing high temperature testing. The heat source is usually covering the specimen, requiring the vibrometer to look through small gaps in the heaters. Another potential problem that can occur when using a vibrometer for high temperature testing is the reflectivity of the specimen surface. The quality of the vibrometer signal is directly proportional to the ability of the specimen to reflect the laser beam back to the vibrometer. If the specimen surface is rough, as in the case of the $\mathrm{C} / \mathrm{C}$ specimens, the vibrometer signal will be noisy. When using the vibrometer to measure strain during room temperature tests, a small piece of reflective tape can be used to improve the signai quality of the vibrometer. For high temperature testing the reflective medium must be able to withstand the temperature without degrading or burning.

High temperature dynamic testing of new composite materials creates new problems in the area of instrumentation. It is difficult to keep thermocouples attached to these materials under high temperature dynamic loading. For some tests this problem can be solved using a pyrometer. To use a pyrometer it must be able to see the specimen surface requiring a temperature measurement. Strain gages also present a problem. They continually fatigue during high cycle dynamic testing and can only be used dynamically at low temperatures. Through the use of strain verses displacement curves a laser vibrometer can be used on some tests to solve this problem. The vibrometer, like the pyrometer, must be able to see the surface strain readings are required on.

For high cycle fatigue tests it is difficult to set up the test to both the pyrometer and the vibrometer could see the test specimen. The quartz lamp fixtures used to hold the lamps that heat the specimens required modifications. Once these modifications were made the non-contact set up with the vibrometer worked very well.

The use of the microspheres to provide a highly reflective high quality return signal to the vibrometer solved the low quality signal problem for this test. It is not known at what temperature the microspheres will no longer work. This was not enough power to take the specimens much above $1000^{\circ} \mathrm{F}$. The limiting factor will probably be the high emissivity paint; however, to verify this further testing is required.

The laser vibrometer can be used to do sine dwell and narrow band random testing. It can also be used to do sine sweeps and in a scanning mode to do mode shapes. The vibrometer can also be used as a feedback control for the shaker system, it is much more reliable 
than strain gages. In high cycle fatigue testing strain gages become more and more unreliable as they accumulate an increasing number of cycles and begin to fatigue. When going high temperature dynamic testing $\left(>1000^{\circ} \mathrm{F}\right)$ strain gages can not be used, in these cases the vibrometer provides the best means available to collect strain data.

The error between the room temperature strain reading the $600^{\circ} \mathrm{F}$ reading is less than 3 percent. This is within the error of the strain gages. Once a room temperature stain verses displacement curve has been developed, strain gages are no longer needed.

Figure 9 shows the strain verses displacement for strain gage with the gage factor compensated for temperature.

\section{Summary}

The Wright Laboratory is the Air Force center for air vehicles, responsible for developing advanced technology and incorporating it into new flight vehicles and for continuous technological improvement of operational air vehicles. The laboratory has been the leader in developing advanced acoustic test capabilities for thirty years, and has recently developed a trio of new test facilities that represent the state of the art in hightemperature, high-intensity acoustic testing and random fatigue testing. These facilities will allow the laboratory scientists and engineers to test the new structures and materials required to withstand the severe environments of captive-carry missiles, augmented lift wings and flaps, exhaust structures of stealthy aircraft, and hypersonic vehicle structures well into the twenty-first century.

\section{High-Temperature Acoustic Testing Requirements}

The Wright Laboratory is developing a hightemperature acoustic testing capability for structures. This effort includes developing techniques for combining the outputs of multiple acoustic drivers into a single progressive wave tube, developing a heating system that is compatible with the high acoustic levels, and developing methods for measuring the response of the structures to be tested. Some of these structures may be actively cooled.

In order to successfully develop and improve this new capability, we are interested in the following particular technical aspects of simulating the combined thermal acoustic environment:

1. Mechanism for generating high-intensity acoustic noise--180 dB

2. Narrowband frequency spectrum control of the noise generator output

3. Effect of combining multiple noise sources

4. Cost reductions to procure noise generators

5. Mechanisms for generating the thermal input to the structure $\left(80-500 \mathrm{BTU} / \mathrm{ft}^{2}-\mathrm{sec}\right)$
6. How to simulate steady-state and thermal trajectories

7. Reliable heat generator in acoustic environment

8. The effects of the thermal environment on the noise environment

9. Methods to measure the high temperature acoustic loads and structural response--high-temperature microphones and strain gages.

\section{References}

1. Kolb, A.W and Magrath, H.A., 1968, "RTD Sonic Fatigue Facility, Design and Performance Characteristics," Shock \& Vibration Bulletin Nr. 37 Supplement, pp. 17-41.

2. Pearson, Jerome, "High Temperature Acoustic Test Facilities and Methods", AGARD Conference Proceedings 549, September 1994.

3. Camden, Michael P. et al, "Strain Measurements for High Temperature Dynamics Fatigue Testing", Second Thermal Structures Conference, Univ of Virginia, June 1994. 


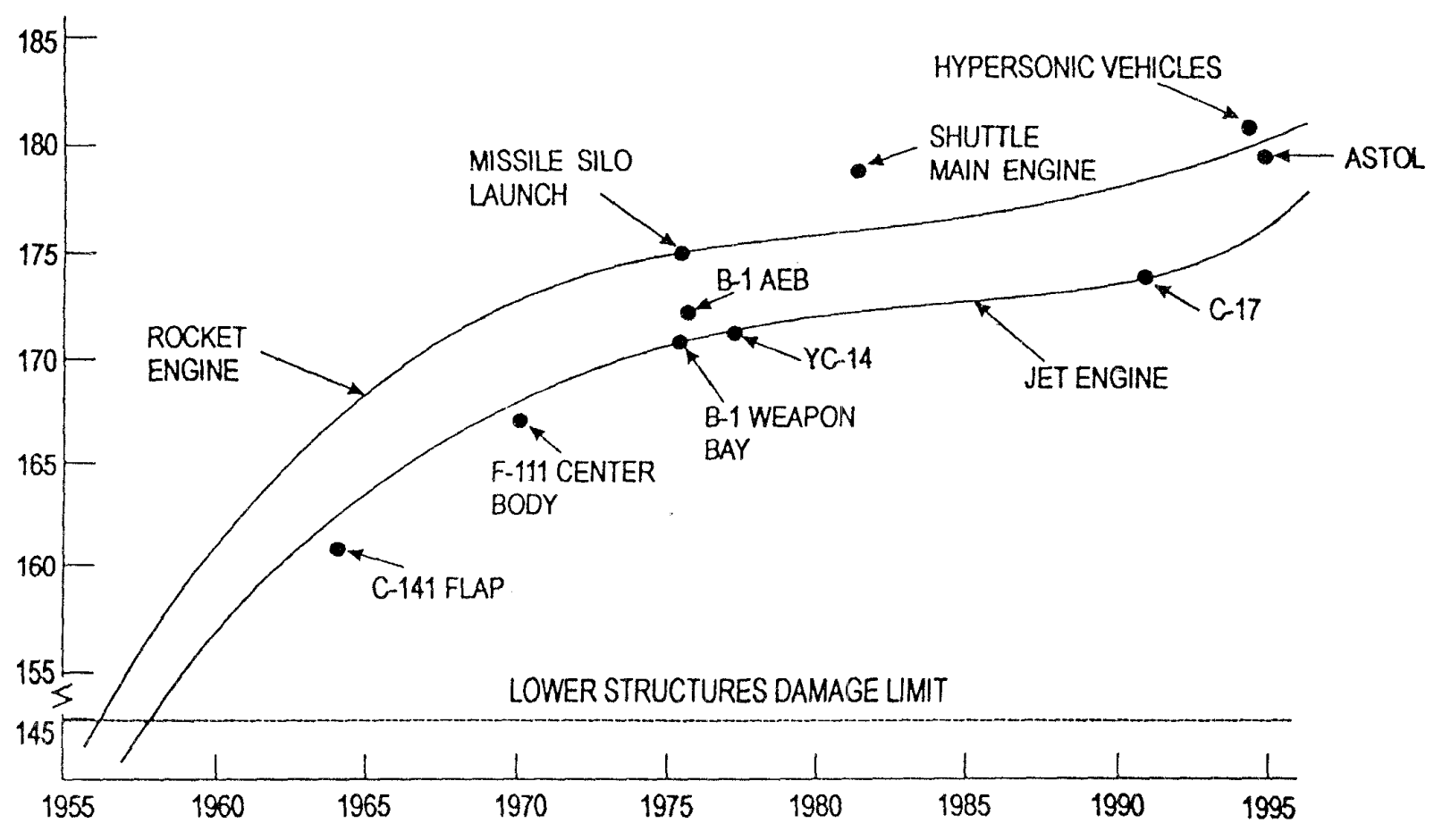

Figure 1. Trends in Acoustic Fatigue

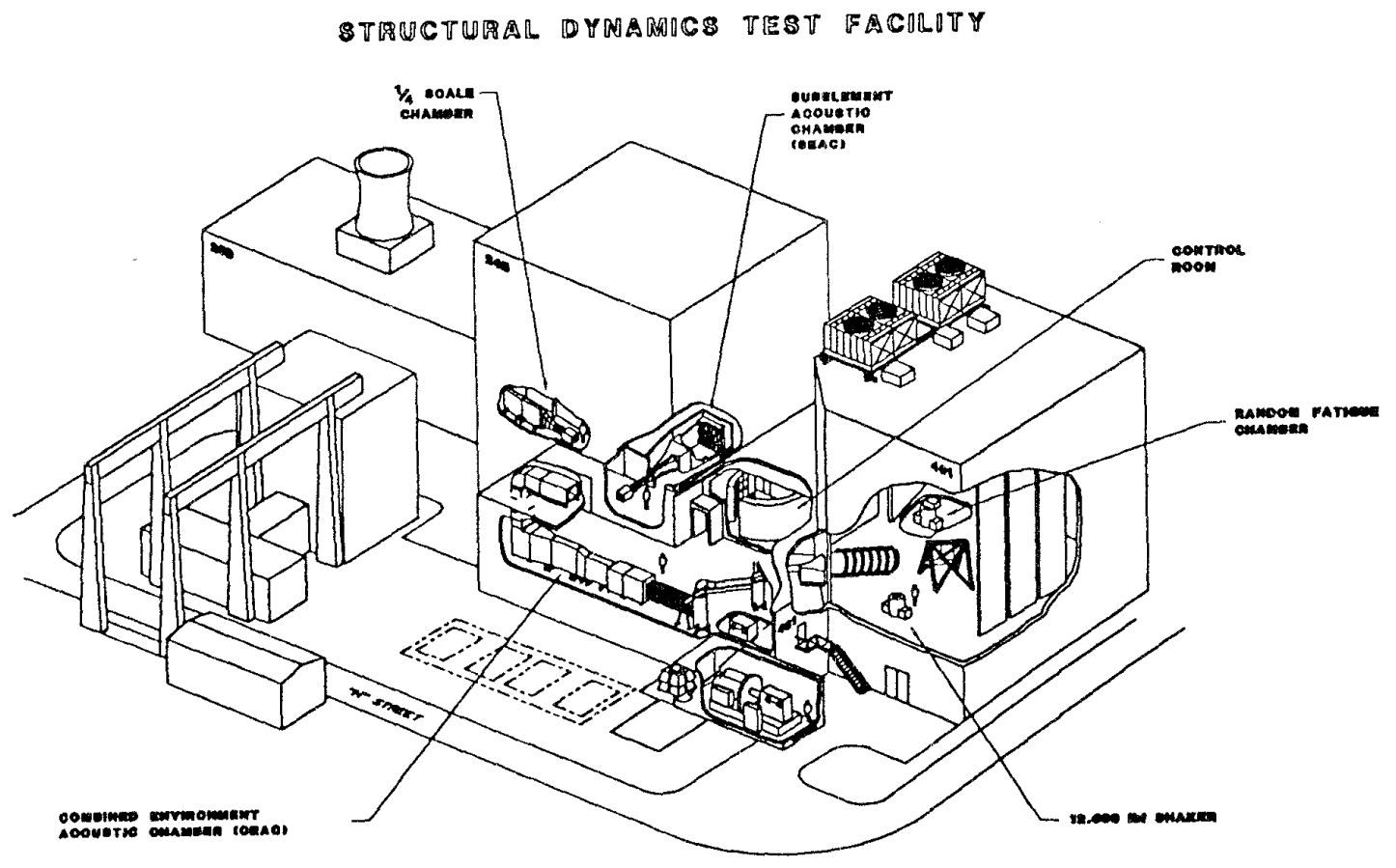

Figure 2. The Wright Laboratory Structural Dynamics Facility 


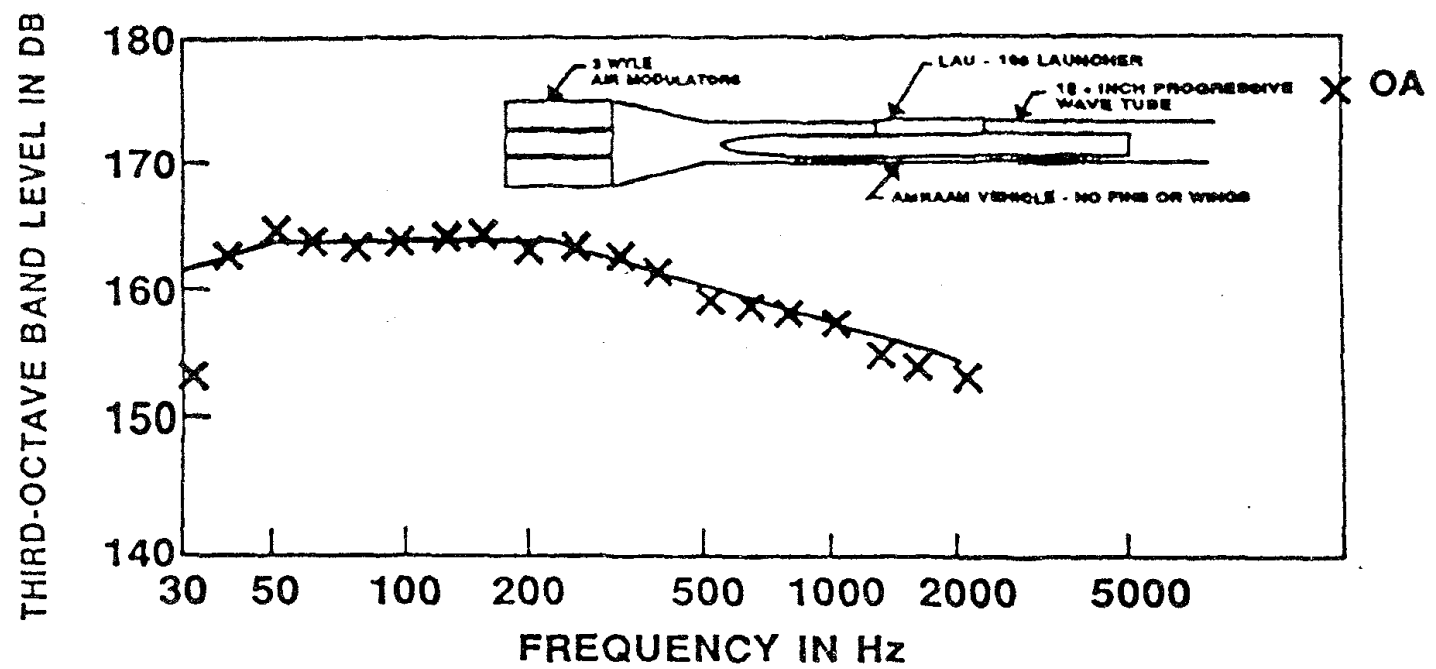

X ACHIEVED

- GOAL

Figure 3. AMRAAM Acoustic Test Spectrum for F-15 Captive Carry

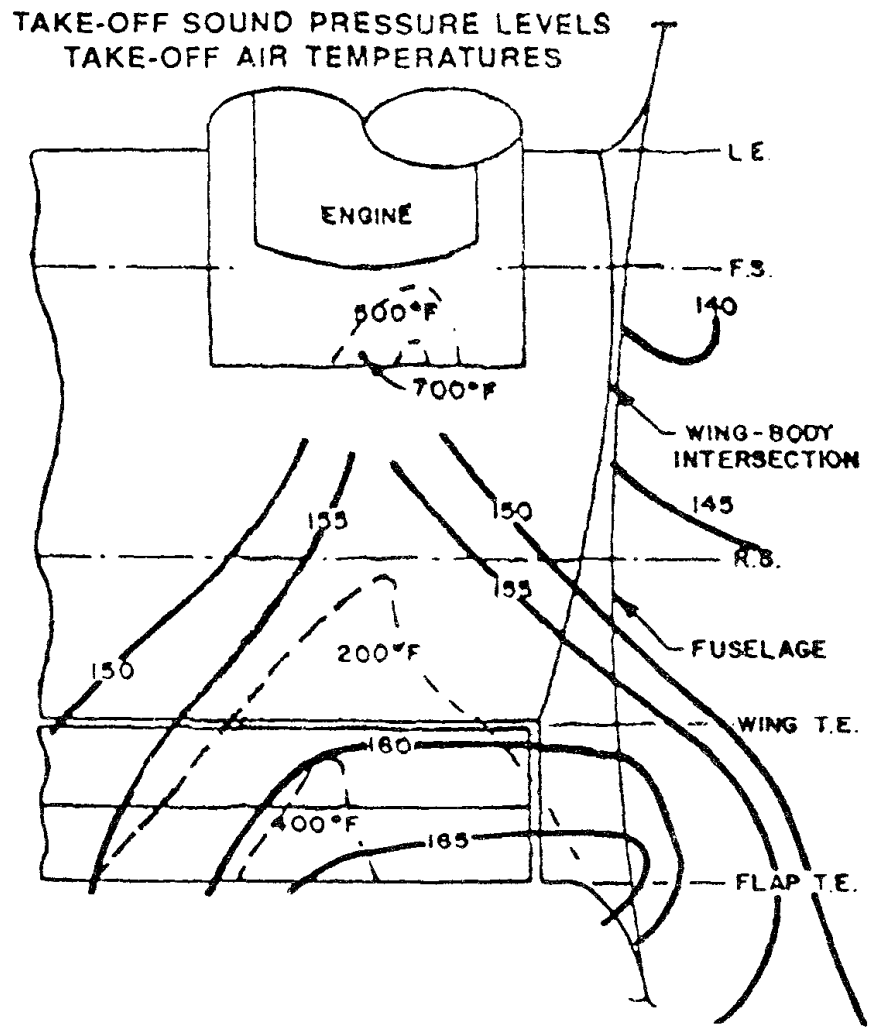

Figure 4. Acoustic and Therma! Environment of High Lift Devices 


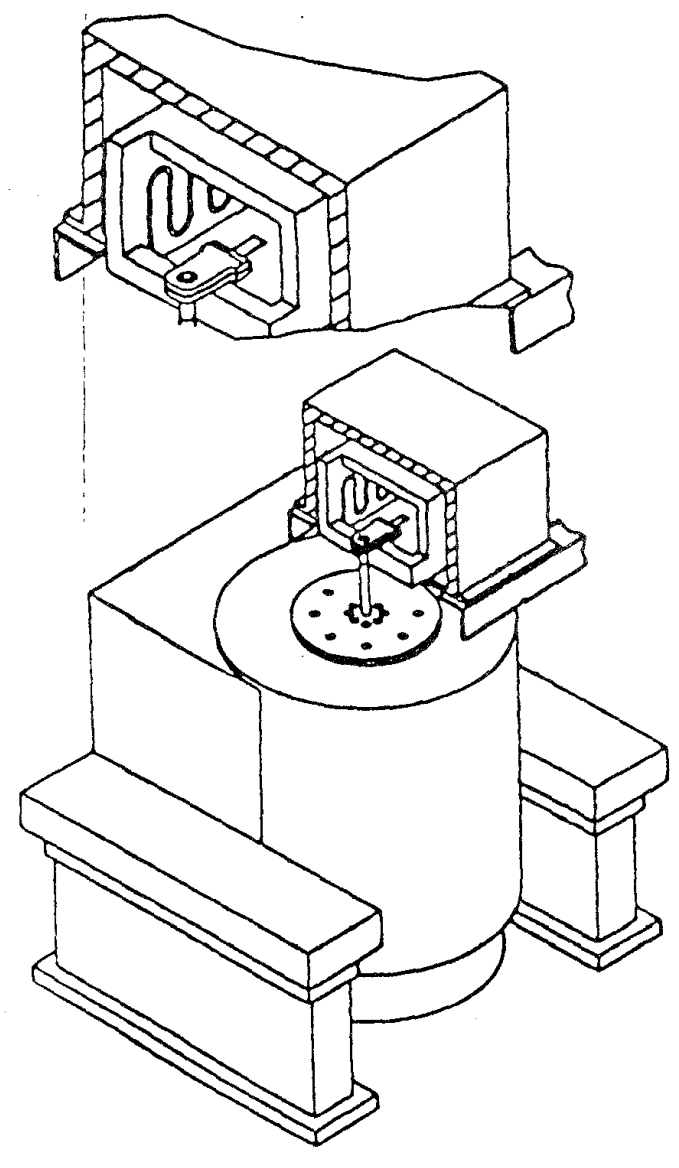

\section{PURPOSE:}

Define Basic Fatigue Properties of Advanced Materials at Severe Environments

\section{CAPABILITIES:}

- Temperature Range from Cryogenic $\left(-250^{\circ} \mathrm{F}\right)$ to High Temp. $\left(2600^{\circ} \mathrm{F}\right.$ )

- Variable Pressure from Vacuum (0.01 torr) to Atmospheric (1000 torr)

- Partial Pressure Gas Environment: $\mathrm{O}_{2}, \mathrm{~N}_{2}, \mathrm{He}$ and $3 \% \mathrm{H}_{2}$

- Shaker-20000 lb, Random, 24000 lb, Sine

- Test Specimen - Up to $3^{\prime \prime} \times T^{\prime \prime}$

Figure 5. Random Fatigue Chamber

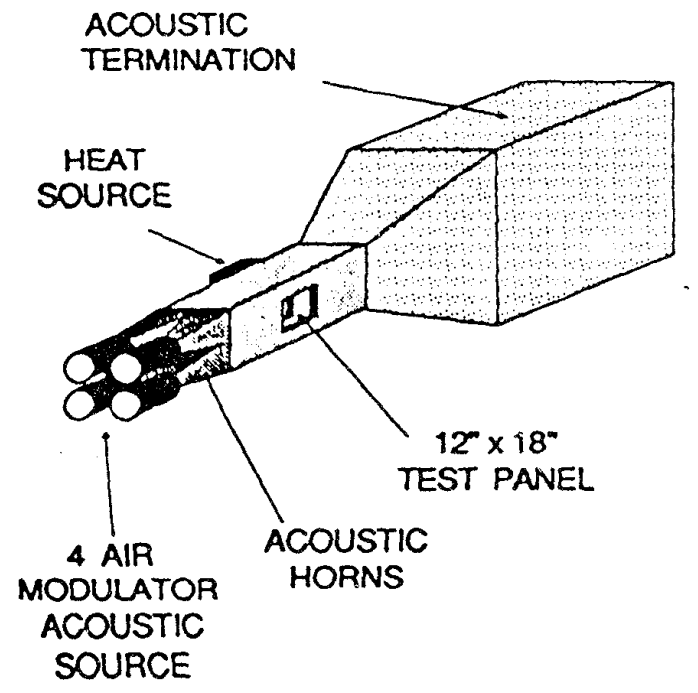

PURPOSE

- DESIGN VERIFICATION FOR COMBINED ENVIRONMENT TESTING

- COMBINED ENVIRONMENT TESTING OF SMALL STRUCTURES

CAPABILITIES

- $180 \mathrm{~dB}$ SPL

- 50 - 300 Btu/ft sec

- $12^{m} \times 18^{\prime \prime}$ PANEL, MAX

Figure 6. Sub-Element Acoustic Chamber 


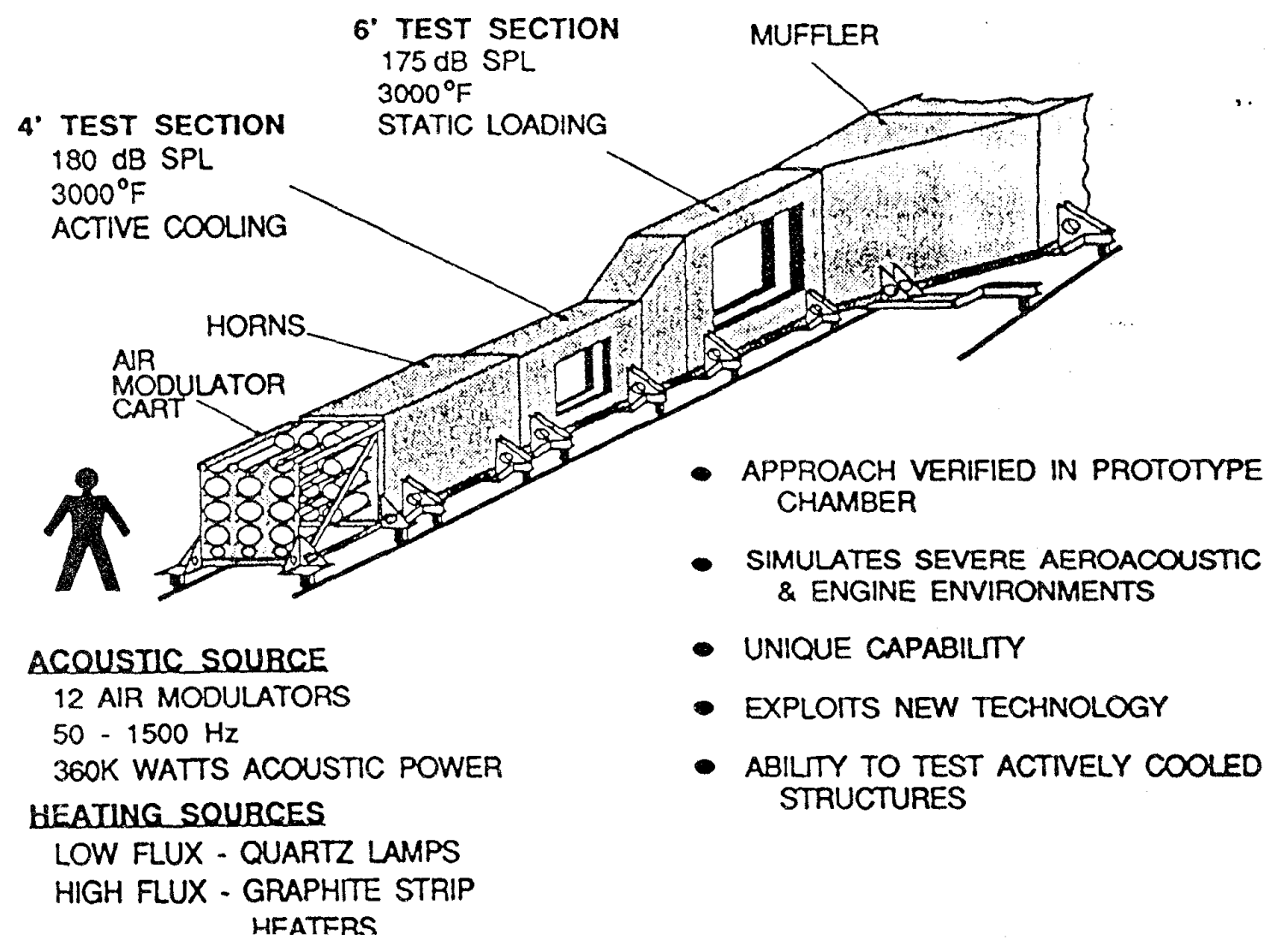

Figure 7. Combined Environment Acoustic Chamber 